\title{
Clinical and Polysomnographic Correlates of Subjective Sleepiness in Mild Obstructive Sleep Apnea
}

\section{Introduction:}

Obstructive Sleep Apnea (OSA) is a heterogeneous disorder with varying symptoms, which do not always correlate with disease severity. Excessive daytime sleepiness (EDS), the cardinal symptom, only weakly correlates with disease severity, measured by the apnea hypopnea index AHI [1]. Nevertheless, the presence of EDS is one of the major indications for treatment of mild OSA (AHI 5 to $<15$ events/hour). Overall, patients with mild OSA are not sleepier than normal controls [2]. However, patients with mild OSA often present with EDS, without another apparent etiology [3]. Some patients report improvement or resolution of symptoms with treatment of OSA, suggesting that OSA may indeed be the etiology of their sleepiness $[4,5]$.

Unfortunately, most clinical assessment tools for EDS are subjective, consisting of patients' reported symptoms and interpretation of scores from validated sleep questionnaires. However, these may be misleading when used in isolation [6] and do not always correctly identify the sleepy vs. the non-sleepy patient. Subjective measures of sleepiness do not differentiate between EDS related to sleep disorders from EDS attributable to other causes. Furthermore, currently available objective measures of EDS are not recommended for routine use in the management of uncomplicated OSA [7]. Although treatment of moderate and severe OSA is generally indicated even in asymptomatic patients due to associated functional and cardiovascular risks, the management of mild OSA often hinges on determining whether a patient is sleepy.

Inasmuch as the AHI only weakly predicts EDS in OSA, alternative polysomnographic predictors of sleepiness have been studied. In a small cohort of patients with $\mathrm{AHI}<10$ events/hour, rapid eye movement (REM) AHI and REM fragmentation corresponded with EDS measured by multiple sleep latency testing [8], but this finding was not corroborated by others [9]. Thus, additional objective correlates of EDS in mild OSA would be useful in making treatment recommendations. Utilizing data from the Apnea Positive Pressure Long-term Efficacy Study (APPLES), this study identified patient characteristics and polysomnographic features which correlated with subjective sleepiness in mild OSA.

\section{Methods}

\section{Study Design and Participants}

The APPLES protocol has been well described [10]. It was a multicenter study carried out at academic and community medical centers. This study analyzes data from a subset of both randomized and non-randomized APPLES participants with AHI of 5 to $<15$ events/hour on baseline polysomnography.

\section{Definitions of Sleepiness}

Excessive daytime sleepiness was defined as a positive response to a question about EDS (vide infra) or an Epworth Sleepiness Score of >10. The EDS question (EDSQ) used was: "Please indicate how often you "feel excessively (overly) sleepy during the day" - (0) Never/ (1) Rarely (once a month or less)/(2) Sometimes (2 - 4 per month)/(3) Often (5-15 per month)/(4) Almost always (16- 30 per month)". Respondents who answered 3 or 4 were classified as "sleepy" (EDSQ positive) while those who answered 0, 1 or 2 were classified as "non-sleepy"(EDSQ negative).

\section{Assessment Tools for Sleepiness, Mood, Cognition and Quality of Life}

Epworth Sleepiness Scale (ESS)

The ESS is a validated 8-item questionnaire, which rates the increasing propensity to fall asleep on a scale of 0 to 3 in commonly encountered daily life situations [11]. The sum of the scores ranges from 0 to 24, and scores $>10$ are regarded as indicative of EDS. 
The SSS quantifies sleepiness on a 7-point scale varying from very alert " 1 " to excessively sleepy "7"[12]. For APPLES, the SSS was administered at 10:00, 12:00, 14:00, and 16:00 on the day following the diagnostic polysomnogram; the variable analyzed was the mean score.

Morningness Eveningness Questionnaire (MEQ)

The MEQ is a validated 19-item questionnaire, which evaluates an individual's inherent circadian rhythm/timing of peak alertness. The sum of the scores is converted to a 5-point scale: definitely morning type (70-86), moderately morning type (59-69), neither type (42-58), moderately evening type (31-41), and definitely evening type (16-30)[13].

\section{Hamilton Rating Scale for Depression (HAM-D)}

The HAM-D is a validated 21-item symptom scale, which assesses severity of depression. APPLES utilized a modified version of HAM-D, (GRID HAM-D) [14]. Items are scored based on intensity and frequency of symptoms and scores are summed. Higher scores reflect more depressive symptoms.

\section{Profile of Mood States (POMS)}

The POMS is a measure of transient mood states with high reliability and validity. It comprises 65 self-rated descriptors on a 5-point scale with instructions to rate each item "at the present time" [15]. These are combined to form the total POMS mood disturbance score which is used in this analysis.

\section{Beck Depression Inventory (BDI)}

The BDI is a validated 21-question multiple-choice self-reported inventory used for measuring the severity of depression [16]. Items are scored on a 4-point scale, where a higher BDI total score suggests a higher level of depression.

\section{Calgary Sleep Apnea Quality of Life Index (SAQLI).}

The SAQLI is a sleep apnea-specific quality of life (QoL) instrument that evaluates the adverse impact of sleep apnea on 4 domains: daily functioning, social interactions, emotional functioning and symptoms[17]. Domain scores are averaged, to yield a total score between 1 and 7. Higher scores represent better QoL.

Mini Mental State Examination (MMSE)

The MMSE is a 11-question instrument testing five areas of cognitive function: orientation, registration, attention and calculation, recall and language. The maximum score is 30 , a score of 23 or below indicates cognitive impairment [18].

\section{Polysomnography}

Polysomnograms were recorded and scored as previously described [10]. An apnea was defined as $>90 \%$ amplitude decrease from baseline of the nasal pressure signal lasting $\geq 10 \mathrm{sec}$.

Hypopneas were scored if there was a $>50 \%$, but $\leq 90 \%$ decrease from baseline, or if there was a clear amplitude reduction of the nasal pressure signal that did not reach the above criterion but was associated with either an oxygen desaturation $>3 \%$ or an arousal, and lasting $\geq 10$ seconds. Obstructive or central apneas were identified by the presence or absence of respiratory effort, respectively. The AHI was the sum of all apneas and hypopneas divided by the total sleep time. All studies were scored at a central site in Stanford University. 


\section{Statistical Analysis}

Statistical tests were performed using Stata/SE (Version 11.0, StataCorp TX USA). First, we modeled our outcome of interest as binary variables: 'non-sleepy', defined as ESS $\leq 10$ and EDSQ negative; 'sleepy', defined as ESS >10, EDSQ positive or both (EDSQ and ESS positive). In the second model, we further categorized sleepiness into three categories based on participants' ESS scores and responses to the EDS question: 1) participants who reported EDSQ positive but ESS $\leq 10 ; 2$ ) participants with ESS $>10$ but reported EDSQ negative, 3) participants who reported EDSQ positive and ESS $>10$.

We then examined the associations between non-sleepy participants and sleepy participants. Continuous variables were compared using the Student's t-test, and data were expressed as means \pm standard deviation. Categorical variables were analyzed using the $\chi^{2}$ test, and data expressed as frequencies or percentages. A one-way ANOVA was conducted to examine the associations between sleepiness and several polysomnographic variables, followed by post hoc comparisons using Bonferroni correction. Statistical significance was set at a $P$ value $<0.05$, twotailed.

\section{Results}

A total of 199 participants had mild OSA. For the initial analysis, EDS was defined in broad terms, using either EDSQ+ or ESS > 10 and 172 participants were analyzed. Fifty-five participants did not provide answers to the EDS question, but 28 of these, scored ESS $>10$ and were included in the sleepy group. The remaining 27 participants could not be categorized due to missing data. By incorporating either definition of EDS, 128 of 172 (74.4\%) participants were sleepy.

Table I shows demographic and clinical characteristics of the sleepy and non-sleepy participants from the initial analysis. There were no significant differences except that the sleepy group was younger ( $46.1 \pm 12.6$ years vs. $53.3 \pm 13.1$ years $)$ and reported more naps per week ( $2.6 \pm 2.9$ vs. $1.3 \pm 1.9)$.

Table II compares assessments of sleepiness, cognition, mood and QoL between the groups. As expected, the sleepy group scored higher on the SSS (3.1 \pm 0.99 vs. $2.5 \pm 0.96)$ and reported lower QoL metrics measured via SAQLI ( $4.5 \pm 0.69$ vs $4.9 \pm 0.61$ ). The sleepy group also had higher depression scores on the HAM-D ( $5.4 \pm 4.7$ vs $3.1 \pm 3.5)$. However the differences in BDI and POMS were not statistically significant. Scores on the MMSE were minimally lower in the non-sleepy group.

The polysomnographic characteristics of the two groups are presented in Table III. The total sleep time (TST) and sleep efficiency (SE) were higher in the sleepy group $(254.2 \pm 106,220.4 \pm 114$ minutes, $\mathrm{p}=0.08 ; 80.2 \pm 12.6,75.7 \pm 14.9 \%$, $\mathrm{p}=0.06$ ), although the differences were not quite statistically significant. The non-sleepy group had slightly higher AHI (12.2 \pm 1.5 vs. $11.2 \pm 2.4$ events/hour, $\mathrm{p}=0.01$ ) and greater desaturation on several indices.

For subsequent analyses, only 144 participants were included since the 55 with missing data could not be categorized using mutually exclusive sleepiness criteria. By screening using ESS, $61(42.3 \%)$ participants qualified as sleepy, while by using the EDSQ, $81(56.3 \%)$ participants were sleepy. Interestingly, 19 (31\%) of the sleepy by ESS cohort screened negative by EDSQ, while 39 (48\%) of the sleepy by EDSQ cohort screened negative by ESS. There was an overlap of only 42 (29.2\%) participants who screened positive by both criteria. Figure I shows the prevalence of sleepiness (by criteria) in mild OSA.

Participants were split into 4 groups: non-sleepy and three mutually exclusive sleepy groups described above. Table IV shows demographic and clinical characteristics of the groups. The nonsleepy group was again older compared to the sleepy groups (53.3 \pm 13.1 vs. $47.6 \pm 9.9$ years vs. $43.4 \pm 13.7$ years vs. $47.6 \pm 12.5$ years). The combined sleepy group reported the most naps per week and the non-sleepy group reported the least naps ( $3.4 \pm 3.8$ vs. $2.0 \pm 2.1$ vs. $2.2 \pm 1.9$ vs. $1.3 \pm$ $1.9, \mathrm{p}=0.01)$. 
Table V compares assessments of sleepiness, cognition, mood and QoL in the 4 groups. All 3 sleepy groups scored higher on the SSS than the non-sleepy group $(3.1 \pm 0.95,3.0 \pm 0.93,2.8 \pm$ 0.67 vs. $2.5 \pm 0.96$ ). The sleepy groups reported lower QoL metrics on the SAQLI when compared to the non-sleepy group, with the combined sleepy group scoring the lowest $(4.4 \pm 0.68$ vs. $4.6 \pm$ 0.68 vs. $4.8 \pm 0.57$ vs. $4.9 \pm 0.61$ ). The sleepy groups had higher depression scores on HAM-D, with the combined sleepy group scoring the highest and the non-sleepy group, the lowest (5.5 $\pm 4.8 \mathrm{vs}$. $5.0 \pm 4.7$ vs. $4.2 \pm 3.7$ vs. $3.1 \pm 3.5$ ). Polysomnographic characteristics of the four groups are compared in Table VI. No statistically significant differences were observed.

\section{Discussion}

Our study showed that a good proportion (25.6\%) of mild OSA patients are not sleepy and the prevalence of sleepiness varied depending on the criteria used. This represents a limitation in accurately estimating the prevalence of sleepiness using subjective methods. With the use of a stringent definition requiring both sleepiness criteria to be met, the prevalence decreased, whereas with a more liberal definition, requiring only one of either criterion, the prevalence increased. Kapur et al reported similar variations in the prevalence of sleepiness in the Sleep Heart Health Study cohort when various definitions of sleepiness were compared [19]. They found that in the mild OSA sub-cohort, $26.7 \%$ had ESS > 10, 14.2\% reported being "sleepy", $17.1 \%$ reported being "unrested" and $38.9 \%$ qualified as sleepy when sleepiness was defined broadly as "any of the 3" above definitions. Similarly, a prior study on Swedish women reported that the prevalence of sleepiness was $28.1 \%$ using standard ESS criteria, but then dropped to $17.2 \%$ when assessed by a single question in the mild OSA sub-cohort [20]. Our study reported higher prevalence rates of sleepiness compared to prior studies. While our study population was not a pure clinical cohort, our data was likely still subject to the effects of referral bias. Similarly, high prevalence rates of sleepiness in mild OSA patients have been reported. A cohort of middle-aged Chinese patients reported a prevalence of $61 \%$ [21] and an adult Korean cohort reported $40.8 \%$ [22]. However, both studies used a less stringent definition of sleepiness, ESS score $\geq 10$. The current analyses and results from these studies emphasize that the absence of sleepiness does not exclude a diagnosis of mild OSA.

Demographic characteristics that may be associated with sleepiness in OSA patients have been described. Younger age has been associated with sleepiness [9, 23] and this is consistent with our findings. Higher BMI has also been independently associated with sleepiness in OSA patients [23, 24]. In our study, participants who qualified as sleepy using both criteria had a slightly higher BMI compared to the other groups. Sleepy participants consistently reported worse QoL and a more depressed mood. Various studies have reported lower QoL in OSA [25] and depressive symptoms have been associated with EDS in OSA [26].

Several polysomnographic correlates have been associated with sleepiness in OSA. These include the presence of sleep fragmentation, evidenced by high arousal indices $[9,23,27,28]$ and alterations in sleep architecture characterized by increased stage N1 sleep and decreased REM and slow wave sleep (SWS) [23, 27]; higher hypoxic burden quantified as higher oxygen desaturation indices, lower oxygen nadir, lower mean saturations or longer duration of hypoxia $[9,23,27,29,30]$. Some studies have found associations between sleepiness and AHI [9, 19, 23, 27], supine AHI [29], REM AHI [8], NREM AHI [31] and apnea index [23, 29]. Polysomnograms of sleepy OSA patients have also been found to be indicative of an increased sleep drive, with increases in TST and SE $[9,27,28,30]$, shorter REM latency [28] and shorter sleep latency [9, 23, $27,30]$. Our study did not corroborate majority of these findings but there was suggestion of an increased sleep drive in the sleepy group evidenced by clinically meaningful increases in TST and SE when compared to non-sleepy counterparts. Moreover, sleepy participants consistently reported more naps.

The aforementioned polysomnographic findings were observed in sleepy cohorts with a broad range of OSA severity and are not always reproducible. Other studies have not found any correlation between sleepiness and arousal indices, sleep fragmentation or sleep stage distribution $[19,30]$. One study actually found that increased SWS correlated with sleepiness in 
OSA[9]. In contrast to existing literature, we found paradoxically higher AHI and worse desaturation indices in the non-sleepy group. We were not able to explain these findings but the observed differences are not clinically meaningful.

A major strength of this study was that it was conducted using a relatively large cohort with detailed characterization of sleep parameters. Participants were screened using attended polysomnography, minimizing the risk of underestimation of sleep-disordered breathing. The study utilized fairly standardized definitions for EDS.

The limitations of the study include that it was not a pure clinical cohort; participants were recruited from clinics and via general advertisement. There was also missing data, which may have impacted study findings.

\section{Conclusion}

The true prevalence of sleepiness in mild OSA is unclear given that sleepiness is measured using various subjective criteria. Excessive daytime sleepiness in mild OSA is more common in younger patients and is associated with worsened mood and QoL. This study suggests that polysomnographic characteristics suggestive of increased sleep drive may correlate with subjective sleepiness in mild OSA. It is possible that some of the prior proposed polysomnographic correlates of EDS in OSA might not be generalizable to mild OSA. Future studies on a larger cohort of patients may help verify these findings. 
Compliance with Ethical Standards

Funding: The current study received no funding

The authors declare that they have no conflict of interest

Ethical approval: All procedures performed in studies involving human participants were in accordance with the ethical standards of the institutional review boards (IRB) at each of the 5 clinical centers (Stanford University, Stanford, CA; University of Arizona, Tucson, AZ; Providence St. Mary Medical Center, Walla Walla, WA; St. Luke's Hospital, Chesterfield, MO; and Brigham and Women's Hospital, Boston, MA) and with the 1964 Helsinki declaration and its later amendments of comparable ethical standards.

This article does not contain any studies with animals performed by any of the authors

Acknowledgements

The Apnea Positive Pressure Long-term Efficacy Study (APPLES) study was funded by contract 5U01-HL-068060 from the National Heart, Lung and Blood Institute. The APPLES pilot studies were supported by grants from the American Academy of Sleep Medicine and the Sleep Medicine Education and Research Foundation to Stanford University and by the National Institute of Neurological Disorders and Stroke (N44-NS-002394) to SAM Technology. In addition, APPLES investigators gratefully recognize the vital input and support of Dr. Sylvan Green, who died before the results of this trial were analyzed but was instrumental in its design and conduct. Administrative Core: Clete A. Kushida, MD, PhD; Deborah A. Nichols, MS; Eileen B. Leary, BA, RPSGT; Pamela R. Hyde, MA; Tyson H. Holmes, PhD; Daniel A. Bloch, PhD; William C. Dement, MD, $\mathrm{PhD}$

Data Coordinating Center: Daniel A. Bloch, PhD; Tyson H. Holmes, PhD; Deborah A. Nichols, MS; Rik Jadrnicek, Microflow, Ric Miller, Microflow Usman Aijaz, MS; Aamir Farooq, PhD; Darryl Thomander, PhD; Chia-Yu Cardell, RPSGT; Emily Kees, Michael E. Sorel, MPH; Oscar Carrillo, RPSGT; Tami Crabtree, MS; Booil Jo, PhD; Ray Balise, PhD; Tracy Kuo, PhD

Clinical Coordinating Center: Clete A. Kushida, MD, PhD, William C. Dement, MD, PhD, Pamela R. Hyde, MA, Rhonda M. Wong, BA, Pete Silva, Max Hirshkowitz, PhD, Alan Gevins, DSc, Gary Kay, PhD, Linda K. McEvoy, PhD, Cynthia S. Chan, BS, Sylvan Green, MD

Clinical Centers

Stanford University: Christian Guilleminault, MD; Eileen B. Leary, BA, RPSGT; David Claman, MD; Stephen Brooks, MD; Julianne Blythe, PA-C, RPSGT; Jennifer Blair, BA; Pam Simi, Ronelle Broussard, BA; Emily Greenberg, MPH; Bethany Franklin, MS; Amirah Khouzam, MA; Sanjana Behari Black, BS, RPSGT; Viola Arias, RPSGT; Romelyn Delos Santos, BS; Tara Tanaka, PhD University of Arizona: Stuart F. Quan, MD; James L. Goodwin, PhD; Wei Shen, MD; Phillip Eichling, MD; Rohit Budhiraja, MD; Charles Wynstra, MBA; Cathy Ward, Colleen Dunn, BS; Terry Smith, BS; Dane Holderman, Michael Robinson, BS; Osmara Molina, BS; Aaron Ostrovsky, Jesus Wences, Sean Priefert, Julia Rogers, BS; Megan Ruiter, BS; Leslie Crosby, BS, RN

St. Mary Medical Center: Richard D. Simon Jr., MD; Kevin Hurlburt, RPSGT; Michael Bernstein, MD; Timothy Davidson, MD; Jeannine Orock-Takele, RPSGT; Shelly Rubin, MA; Phillip Smith, RPSGT; Erica Roth, RPSGT; Julie Flaa, RPSGT; Jennifer Blair, BA; Jennifer Schwartz, BA; Anna Simon, BA; Amber Randall, BA

St. Luke's Hospital: James K. Walsh, PhD, Paula K. Schweitzer, PhD, Anup Katyal, MD, Rhody Eisenstein, MD, Stephen Feren, MD, Nancy Cline, Dena Robertson, RN, Sheri Compton, RN, Susan Greene, Kara Griffin, MS, Janine Hall, PhD

Brigham and Women's Hospital: Daniel J. Gottlieb, MD, MPH, David P. White, MD, Denise Clarke, BSc, RPSGT, Kevin Moore, BA, Grace Brown, BA, Paige Hardy, MS, Kerry Eudy, PhD, Lawrence Epstein, MD, Sanjay Patel, MD

Sleep HealthCenters for the use of their clinical facilities to conduct this research Consultant Teams

Methodology Team: Daniel A. Bloch, PhD, Sylvan Green, MD, Tyson H. Holmes, PhD, Maurice M. Ohayon, MD, DSc, David White, MD, Terry Young, PhD 
Sleep-Disordered Breathing Protocol Team: Christian Guilleminault, MD, Stuart Quan, MD, David White, MD

EEG/Neurocognitive Function Team: Jed Black, MD, Alan Gevins, DSc, Max Hirshkowitz, PhD, Gary Kay, PhD, Tracy Kuo, PhD

Mood and Sleepiness Assessment Team: Ruth Benca, MD, PhD, William C. Dement, MD, PhD, Karl Doghramji, MD, Tracy Kuo, PhD, James K. Walsh, PhD

Quality of Life Assessment Team: W. Ward Flemons, MD, Robert M. Kaplan, PhD

APPLES Secondary Analysis-Neurocognitive (ASA-NC) Team: Dean Beebe, PhD, Robert Heaton, PhD, Joel Kramer, PsyD, Ronald Lazar, PhD, David Loewenstein, PhD, Frederick Schmitt, PhD National Heart, Lung, and Blood Institute (NHLBI)

Michael J. Twery, PhD, Gail G. Weinmann, MD, Colin O. Wu, PhD

Data and Safety Monitoring Board (DSMB)

Seven-year term: Richard J. Martin, MD (Chair), David F. Dinges, PhD, Charles F. Emery, PhD, Susan M. Harding MD, John M. Lachin, ScD, Phyllis C. Zee, MD, PhD

Other term: Xihong Lin, PhD (2 y), Thomas H. Murray, PhD (1 y).

\section{References}

1. Bixler EO, Vgontzas AN, Lin HM, Calhoun SL, Vela-Bueno A, Kales A (2005) Excessive daytime sleepiness in a general population sample: The role of sleep apnea, age, obesity, diabetes, and depression. J Clin Endocrinol Metab 90:4510- 4515. https://doi.org/10.1210/jc.2005-0035

2. Patel S, Kushida C, Walsh J, Shen W et al (2014) Lack of impact of mild obstructive sleep apnea on sleepiness, mood and quality of life. Southwest J Pulm Crit Care 9:44-56. https://doi.org/10.13175/swjpcc082-14

3. Vgontzas AN (2008) Excessive Daytime Sleepiness in Sleep Apnea: It's Not Just Apnea Hypopnea Index. Sleep Med 9:712-714. https://doi.org/10.1016/j.sleep.2008.05.001

4. Rosenthal L, Gerhardstein R, Lumley A et al (2000) CPAP therapy in patients with mild OSA: Implementation and treatment outcome. Sleep Med 1: 215-220. https://doi.org/10.1016/S13899457(00)00012-5

5. Chowdhuri S, Quan SF, Almeida F et al (2016) An Official American Thoracic Society Research Statement: Impact of mild obstructive sleep apnea in adults. Am J Resp Crit Care Med 193:e37-54. https://doi.org/10.1164/rccm.201602-0361ST

6. Quan SF (2013) Abuse of the Epworth Sleepiness Scale. J Clin Sleep Med 9:987. https://doi.org/10.5664/jcsm.3062

7. Littner MR, Kushida C, Wise M et al (2005) Practice parameters for clinical use of the multiple sleep latency test and the maintenance of wakefulness test. Sleep 28:113-21

8. Kass JE, Akers SM, Bartter TC, Pratter MR (1996) Rapid-eye-movement-specific sleepdisordered breathing: A possible cause of excessive daytime sleepiness. Am J Respir Crit Care Med 154:167-169. https://doi.org/10.1164/ajrccm.154.1.8680674

9. Roure N, Gomez S, Mediano O et al (2008) Daytime sleepiness and polysomnography in obstructive sleep apnea patients. Sleep Med 9:727-731. https://doi.org/10.1016/j.sleep.2008.02.006

10. Kushida CA, Nichols DA, Quan SF et al (2006) The Apnea Positive Pressure Long-term Efficacy Study (APPLES): Rationale, design, methods, and procedures. J Clin Sleep Med 2:288-300

11. Johns MW (1991). A new method for measuring daytime sleepiness: The Epworth sleepiness scale. Sleep 14:540-545. https://doi.org/10.1093/sleep/14.6.540

12. Hoddes E, Zarcone V, Smythe H, Phillips R, Dement WC (1973) Quantification of Sleepiness: A New Approach. Psychophysiology 10:431-436. https://doi.org/10.1111/j.14698986.1973.tb00801.x

13. Horne J, \& Ostberg O (1976) A self-assessment questionnaire to determine morningnesseveningness in human circadian rhythms. Int J Chronobiol. 4:97-110.

14. Williams JB, Kobak KA, Bech P et al (2008) The GRID-HAMD: Standardization of the Hamilton depression rating scale. Int Clin Psychopharmacol 23:120-129.

https://doi.org/10.1097/YIC.0b013e3282f948f5 
15. McNair DM, Lorr M, Droppleman LF (1992). Edits Manual for the Profile of Mood States. In: Rev (ed) Edits/Educational and Industrial Testing Service, San Diego, Calif.

16. Beck AT, Steer RA, Brown GK (1996) Manual for the Beck Depression Inventory-II. San Antonio, TX: Psychological Corporation. https://doi.org/10.1002/(SICI)10970142(19991215)86:123.3.CO;2-I

17. Flemons WW, Reimer MA (1998) Development of a disease-specific health-related quality of life questionnaire for sleep apnea. Am J Respir Crit Care Med 158:494-503. https://doi.org/10.1164/ajrccm.158.2.9712036

18. Folstein MF, Folstein SE, McHugh, PR (1975) "Mini-mental state". A practical method for grading the cognitive state of patients for the clinician. J Psychiatr Res 12:189-198. https://doi.org/10.1016/0022-3956(75)90026-6

19. Kapur VK, Baldwin CM, Resnick HE, Gottlieb DJ, Nieto FJ (2005) Sleepiness in patients with moderate to severe sleep-disordered breathing. Sleep 28:472-477

20. Svensson M, Franklin KA, Theorell-Haglöw J, Lindberg E (2008) Daytime sleepiness relates to snoring independent of the apnea-hypopnea index in women from the general population. Chest 134:919-924. https://doi.org/10.1378/chest.08-0847

21. Fong SY, Ho CK, Wing YK (2005) Comparing MSLT and ESS in the measurement of excessive daytime sleepiness in obstructive sleep apnoea syndrome. J Psychosom Res 58:5560. https://doi.org/10.1016/j.jpsychores.2004.05.004

22. Lee SA, Paek JH, Han SH (2015) Sleep hygiene and its association with daytime sleepiness, depressive symptoms, and quality of life in patients with mild obstructive sleep apnea. J Neurol Sci 359:445-449. https://doi.org/10.1016/j.jns.2015.10.017

23. Oksenberg A, Arons E, Nasser K et al (2010) Severe obstructive sleep apnea: Sleepy versus nonsleepy patients. Laryngoscope 120:643-648. https://doi.org/10.1002/lary.20758

24. Ng WL, Orellana L, Shaw JE, Wong E, Peeters A (2017) The relationship between weight change and daytime sleepiness: the Sleep Heart Health Study. Sleep Med 36:109-118. https://doi.org/10.1016/j.sleep.2017.05.004

25. Moyer CA, Sonnad SS, Garetz SL, Helman JI, Chervin RD (2001) Quality of life in obstructive sleep apnea: A systematic review of the literature. Sleep Med 2:477-491. https://doi.org/10.1016/S1389-9457(01)00072-7

26. Lang CJ, Appleton SL, Vakulin A et al (2017) Associations of undiagnosed obstructive sleep apnea and excessive daytime sleepiness with depression: An Australian population study. J Clin Sleep Med 13:575-582. https://doi.org/10.5664/jcsm.6546

27. Sun Y, Ning Y, Huang L et al (2012) Polysomnographic characteristics of daytime sleepiness in obstructive sleep apnea syndrome. Sleep Breath 16:375-381. https://doi.org/10.1007/s11325011-0515-Z

28. Seneviratne U, Puvanendran K (2004) Excessive daytime sleepiness in obstructive sleep apnea: Prevalence, severity, and predictors. Sleep Med 5:339-343. https://doi.org/10.1016/j.sleep.2004.01.021

29. Chevrin R, Aldrich MS (1998) Characteristics of apneas and hypopneas during sleep and relation to excessive daytime sleepiness. Sleep 21:799-806

30. Mediano O, Barceló A, de la Peña M et al (2007) Daytime sleepiness and polysomnographic variables in sleep apnoea patients. Eur Respir J 30:110-113. https://doi.org/10.1183/09031936.00009506

31. Punjabi NM, Bandeen-Roche K, Marx JJ et al (2002) The association between daytime sleepiness and sleep-disordered breathing in NREM and REM sleep. Sleep 25:307-314

\author{
Abbreviations \\ PLM Index: Periodic Limb Movement Index \\ AvSP02: Average Oxygen Saturation \\ TST: Total Sleep Time \\ Desat Index: Desaturation Index
}


Figure I: Prevalence of sleepiness by definition/criteria

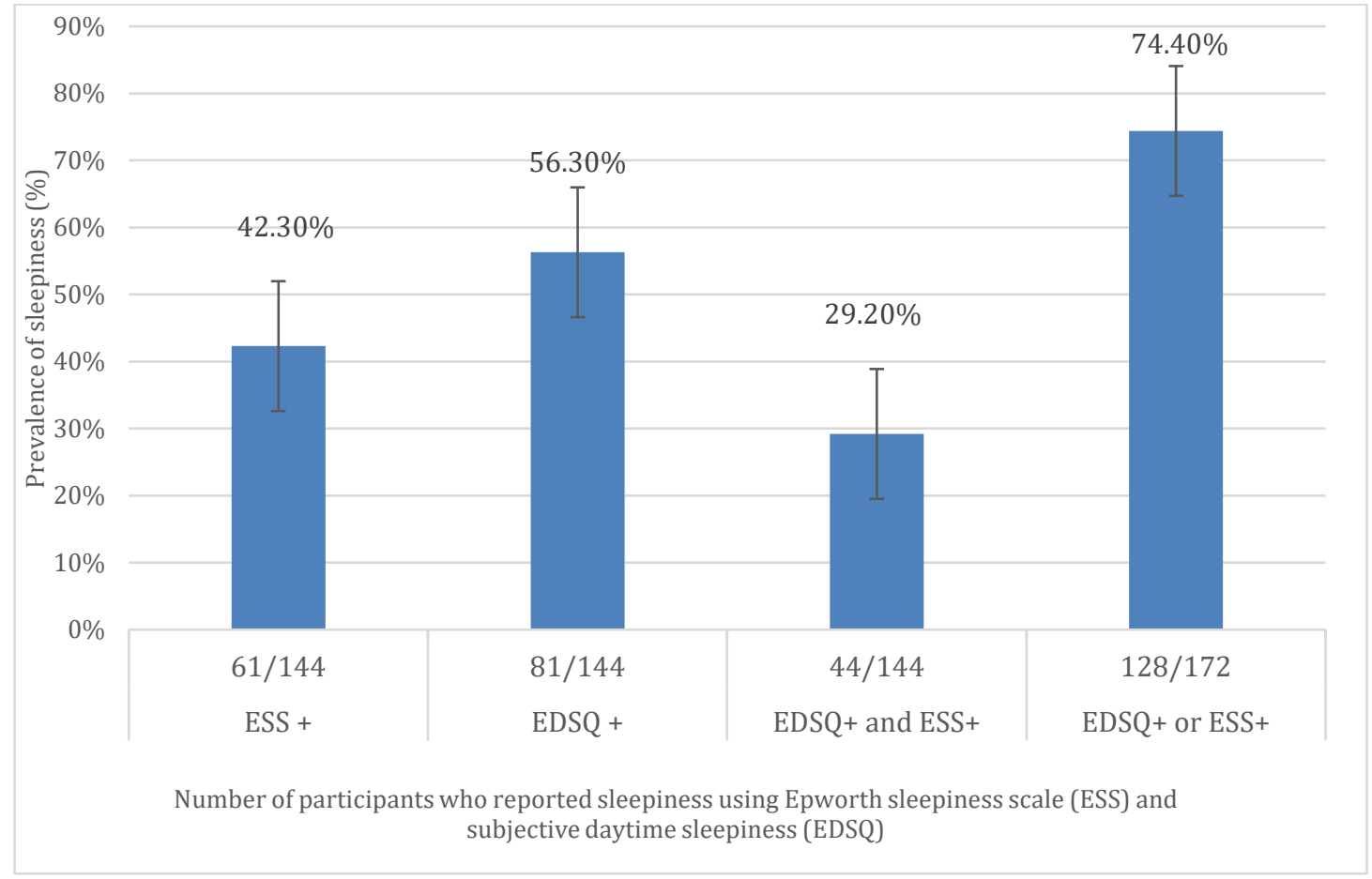




\section{Tables}

Table I : Demographic \& Clinical characteristics of the non-sleepy and sleepy groups.

\begin{tabular}{|l|l|l|l|}
\hline & Non- Sleepy & Sleepy & $P$ value \\
\hline & $\mathrm{N}=44$ & $\mathrm{~N}=128$ & \\
\hline Age (years) & $53.3 \pm 13.1$ & $46.1 \pm 12.6$ & $\mathbf{0 . 0 0 1}$ \\
\hline Males (N/\%)/Females (N/\%) & $26(59.1) / 18(40.9)$ & $66(51.6) / 62(48.4)$ & 0.39 \\
\hline Caucasian (N/\%)/Other (N/\%) & $36(81.8) / 8(18.2)$ & $90(70.3) / 38(29.7)$ & 0.14 \\
\hline BMI $\left(\mathrm{kg} / \mathrm{m}^{2}\right.$ ) & $28.8 \pm 5.5$ & $29.4 \pm 6.2$ & 0.56 \\
\hline Naps per week & $1.3 \pm 1.9$ & $2.6 \pm 2.9$ & $\mathbf{0 . 0 1}$ \\
\hline Caffeine servings per week & $17.9 \pm 15.0$ & $15.6 \pm 15.9$ & 0.39 \\
\hline MEQ & $56.5 \pm 10.0$ & $53.7 \pm 12.7$ & 0.19 \\
\hline
\end{tabular}

Table II : Measures of Sleepiness, Cognition, Quality of Life and Mood in the non-sleepy and sleepy groups.

\begin{tabular}{|l|l|l|l|}
\hline & Non- Sleepy & Sleepy & $P$ value \\
\hline & $\mathrm{N}=44$ & $\mathrm{~N}=128$ & \\
\hline SSS & $2.5 \pm 0.96$ & $3.1 \pm 0.99$ & $\mathbf{0 . 0 0 0 4}$ \\
\hline MMSE & $28.9 \pm 0.77$ & $29.2 \pm 0.99$ & $\mathbf{0 . 0 3}$ \\
\hline SAQLI & $4.9 \pm 0.61$ & $4.5 \pm 0.69$ & $\mathbf{0 . 0 0 0 2}$ \\
\hline POMS & $10.3 \pm 21$ & $16.7 \pm 84$ & 0.62 \\
\hline BDI & $4.9 \pm 4.9$ & $6.7 \pm 5.4$ & 0.06 \\
\hline HAM-D & $3.1 \pm 3.5$ & $5.4 \pm 4.7$ & $\mathbf{0 . 0 0 3}$ \\
\hline
\end{tabular}

Table III: Polysomnographic characteristics of the non-sleepy and sleepy groups

\begin{tabular}{|l|l|l|l|}
\hline & Non-Sleepy & Sleepy & $P$ value \\
\hline & $\mathrm{N}=44$ & $\mathrm{~N}=128$ & \\
\hline AHI_Total & $12.2 \pm 1.5$ & $11.2 \pm 2.4$ & $\mathbf{0 . 0 1}$ \\
\hline AH_REM & $22.3 \pm 14.3$ & $21.3 \pm 13.2$ & 0.67 \\
\hline AHI_NREM & $9.7 \pm 3.0$ & $9.1 \pm 3.6$ & 0.29 \\
\hline Total Sleep Time (min) & $220.4 \pm 114$ & $254.2 \pm 106$ & 0.08 \\
\hline Sleep Efficiency & $75.7 \pm 14.9$ & $80.2 \pm 12.6$ & 0.06 \\
\hline REM_Arousal Index & $46.6 \pm 22.4$ & $46.8 \pm 27.2$ & 0.97 \\
\hline NREM_Arousal Index & $231 \pm 137$ & $217 \pm 130$ & 0.54 \\
\hline Arousal Index & $19.0 \pm 10.8$ & $16.1 \pm 10.4$ & 0.12 \\
\hline N1 sleep (\%) & $12.5 \pm 8.9$ & $12.4 \pm 7.2$ & 0.95 \\
\hline N2 sleep (\%) & $62.2 \pm 13$ & $64.9 \pm 9.4$ & 0.14 \\
\hline N3 sleep (\%) & $5.6 \pm 9.1$ & $4.1 \pm 6.6$ & 0.26 \\
\hline REM sleep (\%) & $19.6 \pm 6.9$ & $18.4 \pm 6.6$ & 0.29 \\
\hline Sleep Latency (min) & $20.4 \pm 22.2$ & $16.9 \pm 21.1$ & 0.35 \\
\hline REM latency (min) & $118.9 \pm 69.1$ & $127.9 \pm 82.9$ & 0.52 \\
\hline PLM Index & $8.1 \pm 15.3$ & $4.6 \pm 13.2$ & 0.15 \\
\hline AvSPO2_REM (\%) & $91.5 \pm 14.7$ & $94.3 \pm 8.8$ & 0.14 \\
\hline AvSPO2_NREM (\%) & $93.9 \pm 2.3$ & $94.8 \pm 2.1$ & $\mathbf{0 . 0 1}$ \\
\hline Time SPO2<85_TST (\%) & $0.54 \pm 2.4$ & $0.03 \pm 0.13$ & $\mathbf{0 . 0 2}$ \\
\hline Time SPO2<85_REM (\%) & $0.29 \pm 1.5$ & $0.001 \pm 0.19$ & $\mathbf{0 . 0 4}$ \\
\hline Time SPO2<85_NREM (\%) & $0.21 \pm 0.99$ & $0.01 \pm 0.07$ & $\mathbf{0 . 0 3}$ \\
\hline Desat_Index_TST & $7.1 \pm 5.7$ & $5.4 \pm 4.4$ & $\mathbf{0 . 0 4}$ \\
\hline Desat_Index_REM & $13.3 \pm 12.3$ & $11.1 \pm 12.9$ & 0.32 \\
\hline Desat_Index_NREM & $5.7 \pm 5.8$ & $4.2 \pm 3.8$ & $\mathbf{0 . 0 5}$ \\
\hline
\end{tabular}


Table IV: Demographic and Clinical characteristics of the non-sleepy, sleepy (ESS+), sleepy (EDSQ+) and sleepy (ESS+ EDSQ+) groups

\begin{tabular}{|c|c|c|c|c|c|}
\hline & $\begin{array}{l}\text { Non sleepy } \\
\text { (EDSQ -, ESS -) }\end{array}$ & $\begin{array}{l}\text { Sleepy } \\
(\mathrm{ESS}+, \text { EDSQ -) }\end{array}$ & $\begin{array}{l}\text { Sleepy } \\
(\text { EDSQ+, ESS -) }\end{array}$ & $\begin{array}{l}\text { Sleepy } \\
(\text { EDSQ+, ESS+) }\end{array}$ & $P$ value \\
\hline & $\mathrm{N}=44$ & $\mathrm{~N}=19$ & $\mathrm{~N}=39$ & $\mathrm{~N}=42$ & \\
\hline Age (years) & $53.3 \pm 13.1$ & $47.6 \pm 9.9$ & $43.4 \pm 13.7$ & $47.6 \pm 12.5$ & 0.01 \\
\hline $\begin{array}{l}\text { Males } \\
(\mathrm{N} / \%) / \text { Females } \\
(\mathrm{N} / \%)\end{array}$ & $\begin{array}{l}26(59.1) / \\
18(40.9)\end{array}$ & $\begin{array}{l}12(63.2) / \\
7(36.8)\end{array}$ & $\begin{array}{l}23(59.0) / \\
16(41.0)\end{array}$ & $\begin{array}{l}20(47.6) / \\
22(52.4)\end{array}$ & 0.59 \\
\hline $\begin{array}{l}\text { Caucasian }(\mathrm{N}, \\
\%) / \operatorname{Other}(\mathrm{N} / \%)\end{array}$ & $\begin{array}{l}36(81.8) / \\
8(18.2)\end{array}$ & $\begin{array}{l}12(63.2) / \\
7(36.8)\end{array}$ & $\begin{array}{l}31(79.5) / \\
8(20.5)\end{array}$ & $\begin{array}{l}30(71.4) / \\
12(28.6)\end{array}$ & 0.36 \\
\hline BMI $\left(\mathrm{kg} / \mathrm{m}^{2}\right)$ & $28.8 \pm 5.5$ & $29.2 \pm 4.5$ & $28.6 \pm 5.6$ & $31.2 \pm 7.2$ & 0.18 \\
\hline Naps per week & $1.3 \pm 1.9$ & $2.2 \pm 1.9$ & $2.0 \pm 2.1$ & $3.4 \pm 3.8$ & 0.01 \\
\hline $\begin{array}{l}\text { Caffeine servings } \\
\text { per week }\end{array}$ & $17.9 \pm 15$ & $12.2 \pm 10.6$ & $17.7 \pm 19.3$ & $17.3 \pm 16.1$ & 0.58 \\
\hline MEQ & $56.5 \pm 10$ & $56.1 \pm 9.9$ & $51 \pm 15.6$ & $55 \pm 10.5$ & 0.18 \\
\hline
\end{tabular}

Table V: Measures of Sleepiness, Cognition, Quality of Life and Mood in the non-sleepy, sleepy (ESS+), sleepy (EDSQ+) and sleepy (ESS+ EDSQ+) groups

\begin{tabular}{|l|l|l|l|l|l|}
\hline & $\begin{array}{l}\text { Non sleepy } \\
\text { (EDSQ -, ESS - })\end{array}$ & $\begin{array}{l}\text { Sleepy } \\
\text { (ESS +, EDSQ -) }\end{array}$ & $\begin{array}{l}\text { Sleepy } \\
\text { (EDSQ+, ESS -) }\end{array}$ & $\begin{array}{l}\text { Sleepy } \\
\text { (EDSQ+, ESS+) }\end{array}$ & $P$ value \\
\hline & $\mathrm{N}=44$ & $\mathrm{~N}=19$ & $\mathrm{~N}=39$ & $\mathrm{~N}=42$ & $3.1 \pm 0.95$ \\
\hline SSS & $2.5 \pm 0.96$ & $2.8 \pm 0.67$ & $3.0 \pm 0.93$ & $\mathbf{0 . 0 1}$ \\
\hline MMSE & $28.9 \pm 0.77$ & $29.4 \pm 0.96$ & $29.1 \pm 1.1$ & $29.2 \pm 1.1$ & 0.24 \\
\hline SAQLI & $4.9 \pm 0.61$ & $4.8 \pm 0.57$ & $4.6 \pm 0.68$ & $4.4 \pm 0.68$ & $\mathbf{0 . 0 0 0 1}$ \\
\hline POMS & $10.3 \pm 21$ & $18 \pm 21$ & $1.2 \pm 148$ & $25.2 \pm 27$ & 0.58 \\
\hline BDI & $4.9 \pm 4.9$ & $5.6 \pm 4.5$ & $7.0 \pm 5.3$ & $6.9 \pm 5.9$ & 0.20 \\
\hline HAM-D & $3.1 \pm 3.5$ & $4.2 \pm 3.7$ & $5 \pm 4.7$ & $5.5 \pm 4.8$ & $\mathbf{0 . 0 5}$ \\
\hline
\end{tabular}


Table VI : Polysomnographic characteristics of the non-sleepy, sleepy (ESS+), sleepy (EDSQ+) and sleepy (ESS+ EDSQ+) groups

\begin{tabular}{|c|c|c|c|c|c|}
\hline & $\begin{array}{l}\text { Non sleepy } \\
\text { (EDSQ -, ESS -) }\end{array}$ & $\begin{array}{l}\text { Sleepy } \\
\text { (ESS +, EDSQ -) }\end{array}$ & $\begin{array}{l}\text { Sleepy } \\
\text { (EDSQ+, ESS -) }\end{array}$ & $\begin{array}{l}\text { Sleepy } \\
\text { (EDSQ+, ESS+) }\end{array}$ & $\begin{array}{l}P \\
\text { value }\end{array}$ \\
\hline & $\mathrm{N}=44$ & $\mathrm{~N}=19$ & $\mathrm{~N}=39$ & $\mathrm{~N}=42$ & \\
\hline AHI_Total & $12.2 \pm 1.6$ & $11.8 \pm 1.3$ & $12.1 \pm 1.5$ & $12.4 \pm 1.5$ & 0.62 \\
\hline AHI_REM & $22.3 \pm 14.3$ & $21.8 \pm 10.3$ & $22.2 \pm 13.8$ & $22.9 \pm 15.2$ & 0.99 \\
\hline AHI_NREM & $9.7 \pm 3.0$ & $10.1 \pm 2.1$ & $9.9 \pm 3.3$ & $10.0 \pm 3.8$ & 0.97 \\
\hline Total Sleep Time (min) & $220.4 \pm 114$ & $265.7 \pm 91$ & $255.2 \pm 105$ & $243 \pm 111.9$ & 0.36 \\
\hline Sleep Efficiency & $75.7 \pm 14.9$ & $82.3 \pm 8.8$ & $80.1 \pm 12.7$ & $78.3 \pm 13.8$ & 0.27 \\
\hline REM_Arousal Index & $46.6 \pm 22.4$ & $41.2 \pm 25.4$ & $51.9 \pm 22.3$ & $45.6 \pm 29.9$ & 0.46 \\
\hline NREM_Arousal Index & $231.3 \pm 137.4$ & $242.6 \pm 137.8$ & $212.4 \pm 137.4$ & $222.3 \pm 123.1$ & 0.85 \\
\hline Arousal Index & $19 \pm 10.8$ & $16.9 \pm 11.8$ & $18.4 \pm 9.7$ & $15.4 \pm 10.2$ & 0.38 \\
\hline N1 sleep (\%) & $12.5 \pm 8.9$ & $13.6 \pm 6.3$ & $11.6 \pm 6.5$ & $12.5 \pm 6.7$ & 0.82 \\
\hline N2 sleep (\%) & $62.2 \pm 13$ & $66.1 \pm 8.4$ & $66.5 \pm 7.9$ & $64 \pm 9.2$ & 0.24 \\
\hline N3 sleep (\%) & $5.6 \pm 9.1$ & $3.8 \pm 5.7$ & $3.2 \pm 5.1$ & $4.7 \pm 7.5$ & 0.49 \\
\hline REM sleep (\%) & $19.6 \pm 6.9$ & $16.5 \pm 6.2$ & $18.5 \pm 4.6$ & $18.6 \pm 6.9$ & 0.36 \\
\hline Sleep Latency (min) & $20.4 \pm 22.2$ & $10.8 \pm 7.2$ & $17.5 \pm 16.9$ & $17.5 \pm 17.4$ & 0.29 \\
\hline REM latency (min) & $118.9 \pm 69$ & $136.9 \pm 94.9$ & $139.1 \pm 66.6$ & $111.7 \pm 82.8$ & 0.34 \\
\hline PLM Index & $8.1 \pm 15.3$ & $3.1 \pm 8.3$ & $3.2 \pm 5.9$ & $5.3 \pm 11.2$ & 0.20 \\
\hline AvSPO2_REM (\%) & $91.5 \pm 14.7$ & $94.6 \pm 2.4$ & $95.1 \pm 1.9$ & $92.7 \pm 15.2$ & 0.50 \\
\hline AvSPO2_NREM (\%) & $93.9 \pm 2.3$ & $94.4 \pm 1.9$ & $95.0 \pm 1.8$ & $94.7 \pm 2.4$ & 0.09 \\
\hline Time sp02<85TST (\%) & $0.54 \pm 2.4$ & $0.01 \pm 0.03$ & $0.01 \pm 0.04$ & $0.04 \pm 0.14$ & 0.23 \\
\hline Time sp02<85REM (\%) & $0.29 \pm 1.5$ & $0.002 \pm 0.01$ & $0.003 \pm 0.02$ & $0.01 \pm 0.34$ & 0.32 \\
\hline Time sp02<85NREM (\%) & $0.21 \pm 0.99$ & $0.01 \pm 0.03$ & $0.01 \pm 0.04$ & $0.004 \pm 0.02$ & 0.27 \\
\hline Desat_Index_TST & $7.1 \pm 5.7$ & $5.0 \pm 3.6$ & $5.7 \pm 4.9$ & $6.6 \pm 4.6$ & 0.37 \\
\hline Desat_Index_REM & $13.3 \pm 12.3$ & $12.2 \pm 12.5$ & $10.3 \pm 13.4$ & $13.8 \pm 14.7$ & 0.65 \\
\hline Desat_Index_NREM & $5.7 \pm 5.8$ & $4.0 \pm 3.0$ & $4.8 \pm 4.2$ & $4.9 \pm 4.0$ & 0.55 \\
\hline
\end{tabular}

